\title{
Emergence of Primary Teeth in Children of Sunsari District of Eastern Nepal
}

\author{
Anita Gupta*, SS Hiremath ${ }^{\dagger}$, SK Singh, S Poudyal, SR Niraula, DD Baral, \\ RK Singh
}

\begin{abstract}
This study assessed the timing and eruption sequence of primary teeth in children of Sunsari district of Eastern Nepal and compared the eruption pattern of males \& females between various, ethnic groups.

Method: This cross-sectional study, included 501 subjects, aged 3 months to 60 months selected by simple random sampling method. The determinant variables such as age, gender, ethnicity, and eruption of teeth were recorded.

Results: This study provides a model data on emergence of primary teeth and number of deciduous teeth in these children. This is a first study of its kind in Nepal. The findings of this study will help as a reference data for optimal use in clinical, academic, and research activities, especially for children of Eastern Nepal.
\end{abstract}

KEY WORDS: Emergence, Eruption, Primary Teeth, Milk Teeth, chronology of tooth eruption.

\section{INTRODUCTION}

Tooth eruption is an important milestone during a child's development; hence most parents are often anxious about the timing of eruption $(1,2)$. An erupted tooth is defined as a tooth with any part of its crown penetrating the gingiva and visible in the oral cavity (1, 3 ). The formation of teeth, development of dentition and growth of craniofacial complex are closely related.4 Several studies have shown variation in the ages at which individual primary teeth erupt as well as variations of eruption pattern between different ethnic and racial groups $(1,4-7)$.

Tooth emergence has not been investigated in Nepalese

$\dagger$ To whom correspondence should be addressed:

Dr. SS Hiremath.

Formerly Associate Professor \& Head, Department of Pedodontics and Preventive Dentistry, College of Dental Surgery, B P Koirala Institute of Health Sciences, Dharan NEPAL

Email: gupanita@yahoo.com,drravi3@gmail.com

Tel: 00977-1-4227149, Fax\# 00977-25-520251,

Mobile: 00977-98415-25594 population \& information on ages of eruption of deciduous teeth used in clinical and academic situation in Nepal is based on other populations like Caucasians (6-11). It has been suggested in the literature that standards for tooth emergences should be derived from the population in which they are to be applied because factors related to deciduous and permanent dentition may vary (12). Estimation of eruption schedule can be a very valuable asset in diagnosis and treatment planning during developmental years, including the diagnosis of developmental oral disturbances during the early childhood period ( 1,712$)$. Dental age is the key factor for implementation of caries prevention programs such as topical fluoride application, age estimation in forensic sciences and anthropology $(1,6-$ 9, 11, 13).

The purpose of the present study was to investigate the timing and sequence of eruption of primary teeth among children of Eastern Nepal and assess the role of gender on eruption pattern, which were compared with other known populations such as the United States of 
America, Saudi Arabia, Iraq and Ireland.

\section{RESEARCH DESIGN AND METHODOLOGY Subjects}

This cross sectional study included 501 healthy children between the ages of 3 months and 60 months. The gender ratio of 1:1.18 favored male children. Table 1 shows age and gender distribution. Children from Sunsari district of eastern Nepal were recruited by stratified random sampling method from August 2004 February 2005.

Parents were informed about the study during the national immunization days at immunization booths. The booths were selected randomly from various urban and semi-urban areas. Parents willing to participate in the study were asked to return with their birth records during the next immunization day. Children of only those parents giving informed consent and producing required birth certificate were included. Children with a known record/history of preterm or with early childhood diseases requiring hospitalization were excluded from the study as these conditions affect tooth eruption. Every child's date of birth was obtained from hospital records/ birth certificates/ nationality certificates and chronological age in months was calculated. Permission to carry out the study was obtained from College of Dental surgery and Public health Section, BPKIHS (Bishweshwor Prasad Koirala Institute of Health Sciences - a deemed Health University of Eastern Nepal).

Table 1. Number of study subjects according to age and gender.

\begin{tabular}{|lllllll}
\hline Age & \multicolumn{3}{l}{ Gender of Subjects } & \multicolumn{3}{l}{ Total } \\
& Boys & & Girls & & \\
& $\mathbf{n}$ & $\%$ & $\mathbf{n}$ & $\%$ & $\mathbf{n}$ & $\%$ \\
\hline 3-12 months & 52 & 10.4 & 46 & 9.2 & 98 & 19.6 \\
\hline 13-24 months & 58 & 11.5 & 48 & 9.6 & 106 & 21.2 \\
\hline 25-36 months & 51 & 10.2 & 47 & 9.4 & 98 & 19.6 \\
\hline 37-48 months & 63 & 12.5 & 51 & 10.2 & 114 & 22.8 \\
\hline 49-60 months & 47 & 9.4 & 38 & 7.6 & 85 & 17 \\
\hline Total & 271 & 54 & 230 & 46 & 501 & 100 \\
\hline
\end{tabular}

\section{Methods}

Clinical examination of the subject was done under torchlight with mouth mirror, tongue blade and dental explorer no. 4 with the subject seated on their parent's lap. Parents were seated on an ordinary chair. Dental chartings were made according to universally accepted Federation Dentaire Internationale (FDI) standards. The emergence stages were classified as given below, which has been explained in detail elsewhere (14):

$0=$ The teeth is not visible in the oral cavity.
$1=$ At least one cusp is visible in the oral cavity.

$2=$ The entire occlusal surface / mesio-distal width of the tooth is visible.

$3=$ The tooth is in occlusion or at the occlusal level if the antagonistic tooth has not fully erupted.

Two examiners (AG\&PS) were calibrated in a pilot study of 20 subjects each in a similar sample. The inter examiner reliability was $100 \%$.

Data processing and analysis was carried out using the statistical package SPSS (15). The student t-test for independent samples was used to assess the statistical significance of the difference in mean age of tooth eruption between males and females at the 5\% probability level.

\section{RESULTS}

There were no significant differences in the mean age of eruption of the teeth in the right and left sides for both the maxilla and mandible; hence, a summary statistics comparing the mean age of tooth eruption of both the genders on the right side has been presented in Table 2.

Table 2. Summary statistics of mean ages (months) at eruption \pm standard deviation (SD) of primary teeth in children of eastern Nepal.

\begin{tabular}{lllllll}
\hline Tooth & Boys & & Girls & \multicolumn{2}{c}{ Both Genders } \\
& Mean & SD & Mean & SD & Mean & SD \\
\hline 51 & 12.67 & 2.31 & 10.33 & 3.08 & 11.11 & 2.93 \\
\hline 52 & 14.00 & 4.90 & 11.50 & 0.71 & 13.17 & 4.02 \\
\hline 53 & 19.10 & 4.31 & 18.80 & 11.73 & 19.00 & 7.16 \\
\hline 54 & 15.86 & 2.12 & 14.71 & 4.82 & 15.29 & 3.63 \\
\hline 55 & 26.67 & 3.79 & 25.00 & 5.10 & 25.71 & 4.31 \\
\hline 81 & 10.50 & 0.71 & 9.50 & 2.12 & 10.00 & 1.41 \\
\hline 82 & 13.50 & 0.71 & 12.00 & 0.72 & 12.75 & 0.96 \\
\hline 83 & 21.43 & 3.46 & 21.50 & 7.78 & 21.44 & 4.07 \\
\hline 84 & 14.40 & 5.59 & 16.25 & 2.36 & 15.22 & 4.32 \\
\hline 85 & 25.33 & 8.09 & 27.00 & 0.72 & 25.57 & 7.41 \\
\hline *Federation Dentaire Internationale (FDI) toothnotations are used.
\end{tabular}

The mandibular central incisors were the earliest category of teeth to erupt. The maxillary central incisors erupted at about 11 months followed by the maxillary and mandibular laterals respectively. The first molars of both the jaws erupted earlier than the canines. The mandibular and maxillary second molars erupted at a mean age of about 25.5 months for both genders. The length of time from eruption of the first tooth to the last tooth was 14 and 14.83 months in maxilla and mandible respectively in boys, whereas in girls the duration was 14.7 and 17.5 months respectively.

There is a general tendency for the teeth to erupt earlier in girls than boys both in the maxilla and mandible except for the mandibular first molars which erupt late in girls. However, the difference was not statistically significant at the 5\% confidence level.

Comparisons from studies between indigenous 
populations from the United States of America, Saudi Arabia, Iraq and Ireland are presented in Tables 3 and 4 (3, 16-19). The eruption of the incisors showed slight delay in Nepalese male children when compared to children of other nationalities, however the results of other teeth are similar. The order of eruption of the primary teeth showed that mandibular incisor teeth erupted earlier than maxillary incisors in both genders. Eruption of maxillary canine, first molar and second molars was earlier than their mandibular counterparts in girls, whereas in boys all mandibular teeth erupted earlier except for the canines.

Table 3. Comparison of mean ages (months) at eruption of primary teeth in boys of various nationalities.

\begin{tabular}{llllll}
\hline Tooth* & Nepal & Saudi & Iraq & Iceland & USA \\
\hline 51 & 12.67 & 11.19 & 10.70 & 8.99 & 9.36 \\
\hline 52 & 14.00 & 13.09 & 10.10 & 10.38 & 12.00 \\
\hline 53 & 19.10 & 21.14 & 18.80 & 17.59 & 21.00 \\
\hline 54 & 15.86 & 16.88 & 16.30 & 15.10 & 17.52 \\
\hline 55 & 26.67 & 28.16 & 26.00 & 26.13 & 30.96 \\
\hline 71 & 10.50 & 8.44 & 9.20 & 8.03 & 7.20 \\
\hline 72 & 13.50 & 14.44 & 14.00 & 12.08 & 13.08 \\
\hline 74 & 21.43 & 21.03 & 19.00 & 19.16 & 20.88 \\
\hline 75 & 14.40 & 17.17 & 16.90 & 16.16 & 16.56 \\
\hline
\end{tabular}

*Federation Dentaire Internationale (FDI) tooth notations are used.

Table 4. Comparison of mean ages (months) at eruption of primary teeth in girls of various nationalities.

\begin{tabular}{llllll}
\hline Tooth* & Nepal & Saudi & Iraq & Iceland & USA \\
\hline 51 & 10.33 & 11.20 & 10.60 & 9.21 & 8.76 \\
\hline 52 & 11.50 & 13.31 & 11.40 & 10.16 & 11.76 \\
\hline 53 & 18.80 & 21.03 & 19.90 & 17.98 & 20.76 \\
\hline 54 & 14.71 & 16.90 & 16.40 & 14.95 & 16.32 \\
\hline 55 & 25.00 & 28.25 & 27.00 & 25.11 & 31.44 \\
\hline 71 & 9.50 & 8.49 & 8.40 & 6.89 & 7.68 \\
\hline 72 & 12.00 & 14.61 & 14.30 & 11.75 & 13.32 \\
\hline 73 & 21.50 & 21.10 & 20.30 & 18.14 & 20.52 \\
\hline 74 & 16.25 & 17.13 & 17.00 & 15.43 & 16.44 \\
\hline 75 & 27.00 & 27.97 & 25.10 & 23.74 & 29.52 \\
\hline
\end{tabular}

*Federation Dentaire Internationale (FDI) tooth notations are used.

\section{DISCUSSION}

The mean times for eruption of primary teeth have been determined for most population groups $(3,14)$. A thorough search of Medline on the internet and the past published journals from Nepal revealed no reported data on teeth emergence for Nepalese populations. Also, the standards for the eruption of deciduous teeth used in most Nepalese health institutions are based on
Caucasian population (7). A review of the literature shows there are differences in eruption times between populations mainly due to variations in the constitutions and environment of the groups investigated thus, highlighting the importance of this study to the Nepalese population $(6,12,14)$.

The age of emergence of each primary tooth was established for both genders (Table 2), and the mean age and standard deviation for tooth eruption of all primary teeth in this study were compared with the results obtained in studies of indigenous populations from the United States of America, Saudi Arabia, Iraq and Ireland (3, 16-19). These studies have utilized the same design and method for estimation of tooth emergence and hence the results have been compared. The results suggested slightly delayed eruption of incisor teeth in Nepalese children compared to all other groups. Canines, first and second molars erupted slightly early in both genders except the second primary molar, which erupted earlier in Iraq and Ireland groups.

The order of eruption of primary teeth is given in Figure 1. This pattern of emergence of primary teeth is slightly different as compared to other studies (3, 5, 7, $8,14)$. Logan and Kronfeld have suggested that lateral incisors, canines and first molars erupt earlier in maxilla as compared to their mandibular counterparts (8). However in our study sequence of eruption of maxillary canine, first molar and second molars was earlier in girls than their mandibular counterparts, whereas in boys all mandibular teeth erupted earlier except the canines.

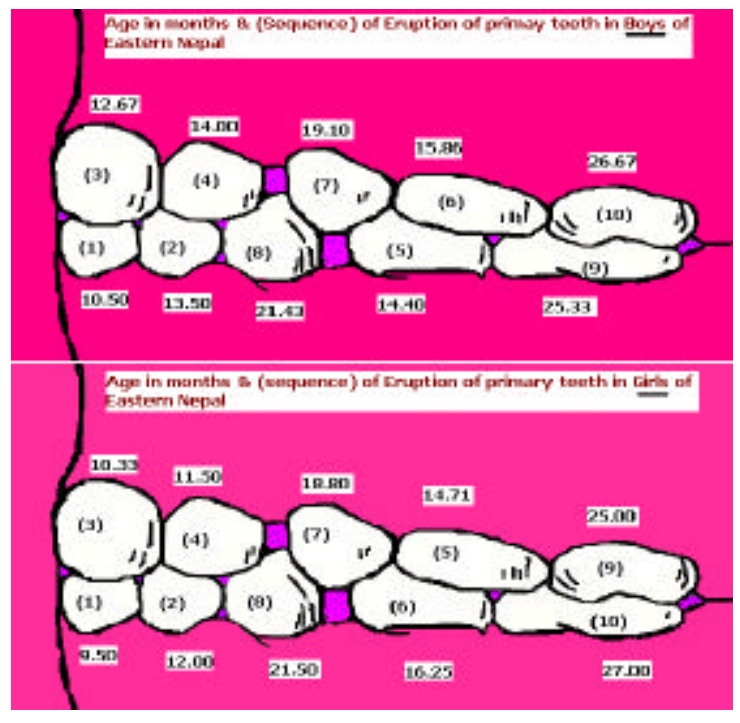

Figure 1. Order (within brackets) \& Chronology (age in months) of eruption of primary teeth in Boys \& Girls of Eastern Nepal. Girls: Sequence of eruption of maxillary canine, first molar \& second molars was earlier than their mandibular counterparts, whereas in boys all mandibular teeth erupted earlier except the canines. 
In this study there was a general tendency for teeth to erupt earlier in girls for both jaws, although the difference was not statistically significant. This is in agreement with the findings of some other studies, except that a few authors refer to statistically significant sex differences, at least for some teeth (8, 24-29).

Eruption of primary teeth occurred in 4 active periods similar to other studies, except for the difference in timing $(1,16,18-20)$. The first phase: central and lateral incisors emerging within 14 months in both jaws. A rest interval of about 2 months in the mandible and the maxilla followed before eruption of the first molars (phase 2). After a resting period of about 6 and 4 months in the mandible and maxilla respectively, canines erupted (phase 3 ). The last phase was the eruption of the second molars that occurred after a pause of about 4 and 6.7 months in the mandible and maxilla respectively.

Variation in the chronology of eruption has been studied extensively. Most studies attribute the differences to influential factors such as nutrition, socio-economic status, climate, and environmental factors such as fluoride content in drinking water. However, the results of these studies are inconsistent and inconclusive with regards to a single factor $(10,11$, 16, 21-29). The differences in fluoride content of drinking water and vast diversity in geographic, environmental and climatic conditions prevailing over short distances in Eastern Nepal make it difficult to single out these factors in our study population and hence the impact of these indicators were not evaluated in this study.

Preterm birth, diseases in early months of life affect the time of tooth eruption. In one study, the timing of deciduous teeth eruption in preterm children was different in comparison with children born after fullterm gestation and depended on the baby's maturity by birth (19). The diseases of the first months of life had a negative impact on the time of tooth eruption in the study (19). Therefore, our study design included only children with a history of full term gestation. Children with diseases in early life time or requiring hospitalization were excluded by a thorough history taking during the screening of the study subjects.

The objective of this study is to establish baseline data of eruption for primary dentition in children from Eastern Nepal. A delay in deciduous teeth eruption could be a sign of a systemic disease, and its observation may lead to a diagnosis of such diseases as hypothyroidism $(3,7)$. Dental ages have also been utilized in the study of the relationships between dental and skeletal maturation rates for anthropological as well as clinical use in dentistry $(3,12)$. The tooth emergence data is a guide to the length of time for which teeth have been exposed to possible attack by caries, which advocate dental-age-appropriate institution of caries control measures like pit and fissure sealants and topical fluorides.

Differences in tooth eruption ages might have resulted because of genetic, climatic, and socioeconomic conditions prevailing in this region. Historically, Nepalese population has had intermingling of races. The influence of ethnicity on tooth emergence warrants further study. The relative bias that might have creeped in because of multiethnic nature of our population is being investigated by the present authors, in the next part of the study; which intends to study the tooth eruption ages for primary as well as permanent dentition in different ethnic groups of this region. The lack of controls for socio-economic conditions and climate are a few limitations of this study, which will have to be addressed in future studies of this region.

\section{CONCLUSION}

The results suggested delayed eruption of incisor teeth in Nepalese children compared to other groups. Canines, first and second molars erupted slightly earlier in both genders except the second primary molar, which erupted earlier in children from Iraq and Ireland. The order of eruption of primary teeth in girls was different as compared to boys. Sequence of eruption of maxillary canine, first molar and second molars was earlier than their mandibular counterparts in girls whereas in boys, all mandibular teeth erupted earlier except the canines.

The findings of this study establish a new chronological table for eruption of primary teeth in children of Nepal. This data will have a significant role for optimal use in preventive approaches to caries, orthodontic, clinical, academic, anthropological, research and forensic applications.

\section{ACKNOWLEDGEMENTS}

The authors are grateful to our honourable vicechancellor Prof. Loke Bikram Thapa for kind support. We would like to thank all the parents for allowing their children to participate in the study. Also, our sincere thanks to: Mr. Umeshlal Karna, supervisor Public Health, BPKIHS \& Dr. Prakash Baral \& Dr. Sylvia Hada formerly, PG students at BPKIHS.

\section{REFERENCES}

1. Pahkala R, Pahkala A, Laine T. Eruption Pattern of Permanent Teeth in a Rural Community in Northeastern Finland. Acta Odont Scand. 1991; 49: 3419.

2. Savara BS, Steen JC. Timing and Sequence of Eruption of Permanent Teeth in a Longitudinal Sample of Children from Oregon. JADA 1978; 99: 209-14.

3. Al-Jasser NM, Bello LL Time of Eruption of Primary Dentition in Saudi Children. J Contemp Dent Pract. 2003; 15;4 (3):65-75.

4. Lysel L, Magnusson B, Thilander B. Time and Order of Eruption of the Primary Teeth. A Longitudinal Study. Odontol Revy. 1962; 13:217-234.

5. Ramirez O, Planells P, Batberia E. Age and Order of Eruption of 
Primary Teeth in Spanish Children. Community Dent Oral Epidemiol. 1994; 22(1):56-9.

6. Hitchcock NE, Gilmour AI, Gracey M, et. al. Australian Longitudinal Study of Time and Order of Eruption of Primary Teeth. Community Dent Oral Epidemiol. 1984; 12(4):260-3.

7. Lunt RC, Law DB. A Review of the Chronology of Eruption of Deciduous Teeth. J Am Dent Assoc. 1974; 89(4):872-9.

8. Logan WHG and Kronfeld As quoted in Eruption of teeth: local, systemic and congenital factors that influence the process. Ralph E McDonald and David R Avery editors' dentistry for the child and adolescent. Sixth edition. Mosby year book Inc London; 1994: 186-215.

9. Baghdady VS, Ghose LJ. Eruption Time of Primary Teeth in Iraqi Children. Community Dent Oral Epidemiol. 1981; 9(5):245-6.

10. Lavelle CL. A Note on the Variation in the Timing of Deciduous Tooth Eruption. J Dent. 1975; 3(6):267-70.

11. Robinow M. The Eruption of Deciduous Teeth. Factors Involved in Timing. Env Child Health (Spec Issue) 1973; 19:200-5.

12. Mugonzibwa EA, Kuijpers-Jagtman AM, Laine-Alawa MT, van't Hof MA. Emergence of Permanent Teeth in Tanzanian Children. Community Dent Oral Epidemol. 2002; 30:455-62.

13. Clemens EMB, Davids-TE, Pickett KG. Time of Eruption of Permanent Teeth in British Children in 1947-8. Br Med J. 1953; 1:1421-1424.

14. Damodar Swami, Mishra VK, Bahl L, Rao MC. Age Estimation from Eruption of Temporary Teeth in Himachal Pradesh. JFMT 1992; 9(3-4):3-7.

15. SPSS Inc. The Statistical Package for the Social Sciences- 11. Chicago, IL: SPSS; 2001.

16. Darlberg AA. Criteria of Individuality in the Teeth. J Forens Sci. 1957; 2:389-421.

17. Houpt MI, Adu-Aryee S, Graninger RM. Eruption Times of Permanent Teeth in the Brong Ahafo Region of Ghana. Am J Orthod. 1967; 53(2):95-9.
18. Lee MMC, Low WD, Chang KS. Eruption of the permanent dentition of Southern Chinese children in Hong Kong. Arch Oral Biol 10(6):849-61; 1965.

19. Magnusson TE. Emergence of Primary Teeth and Onset of Dental Stages in Icelandic Children. Community Dent Oral Epidemiol. 1982; 10(2):91-7.

20. Hayes RL, Mantel N. Procedures for Computing the Mean Age of Eruption of Deciduous Teeth. J Dent Res. 1958; 38:938-947.

21. Sato S, Ogiwara Y. Biostatistic Study of the Eruption Order of Deciduous Teeth. Bull Tokyo Dent Coll. 1972; 12(1):45-76.

22. Fergusson AD, Scott RB, Bowkin H. Growth and Development of Negro Infants: Comparison of Deciduous Dentition in Negro and White Infants, a Preliminary Study. J Pediatr. 1957; 50:327331.

23. Friedlaender JS, Bailit HL. Eruption Times of the Deciduous and Permanent Teeth of Natives on Bougainville Island, Territory of New Guinea: a Study of Racial Variation. Hum Biol. 1969; 41(1): 51-65.

24. Roche AF, Barlela DH, Maritz JS. Deciduous Eruption in Melbourne Children. Aust Dent J. 1964; 9:106-108.

25. Sandles HC. The Eruption of Deciduous Teeth. J Pediatr. 1944; 25:140-147.

26. Yun DJ. Eruption of Primary Teeth in Korean Rural Children. Am J Phys Anthropol. 1957; 15:261-268.

27. McGregor IA, Thomson AM, Billewicz WZ. The Development of Primary Teeth in Children from a Group of Gambian Villages, and Critical Examination of its Use for Estimating Sge. Br J Nutr. 1968; 22(2):307-14.

28. Doering CR, Allen MF. Data on Euption and Caries of Primary Teeth. Child Develop. 1942; 13:113-119.

29. Garn SM, Smith BH. Patterned Asymmetry in Tooth Emergence Timing. J Dent Res. 1980; 59(9):1526-7.

Dr. Anita Gupta is a dental surgeon at College of Dental Surgery, BPKIHS a deemed university of health sciences in Nepal. She has research interests in oral cancer and dental anthropology.

Dr. SS Hiremath is an Associate Professor \& formerly the Head of the department of Pedodontics and Preventive Dentistry at BPKIHS. His research interests include pediatric dental anthropology, pediatric forensic odontology, and dental material science.

Dr. SK Singh is an assistant professor and is in charge of Prosthodontics in BPKIHS. He has research interests in dental anthropology, evidence based dentistry and maxillofacial Prosthetics.

Dr. Poudyal S is a dental surgeon at College of Dental Surgery, BPKIHS. She has research interests in oral cancer and oro-facial growth and development.

SR Niraula is a biostatistician at BPKIHS. He has research interests in community health and oral cancer.

DD Baral, is a biostatistician at BPKIHS. He is involved in training of health statistics and informatics. His interests are hospital database management and Health Management Information System in rural health care services.

Prof. RK Singh was the former chief of College of Dental Surgery, BPKIHS. He has a vast research experience in dental material science, maxillofacial prosthetics, and research methodology and curriculum development. 